\title{
Nitric oxide measured with single-breath and tidal-breathing methods in asthma and COPD
}

\author{
S.R. Rutgers, R.J. Meijer, H.A.M. Kerstjens, Th.W. van der Mark, G.H. Koëter, D.S. Postma
}

Nitric oxide measured with single-breath and tidal-breathing methods in asthma and COPD. S.R. Rutgers, R.J. Meijer, H.A.M. Kerstjens, Th.W. van der Mark, G.H. Koëter, D.S. Postma. CERS Journals Ltd 1998.

ABSTRACT: Nitric oxide (NO) can be measured in exhaled air with the single-breath (SB) and tidal-breathing (TB) methods. To allow comparison between different laboratories, a European Respiratory Society task force recently reported guidelines for standardization of both methods. To facilitate comparison between laboratories further, this study investigated whether there is a difference between NO values measured with SB and TB methods in subjects with asthma or chronic obstructive pulmonary disease (COPD), and in healthy subjects. Moreover, the differences between groups were studied and the influence of smoking in asthma was assessed.

Sixteen atopic nonsmoking asthmatics, 16 atopic currently smoking asthmatics, 16 nonatopic nonsmoking healthy controls, 16 nonatopic exsmokers with COPD and 16 nonatopic exsmoking healthy controls were studied.

NO concentrations differed substantially between both methods. Mean NO concentrations were higher with the SB than with the TB method in nonsmoking and in smoking asthmatics and especially so with the higher NO values. Furthermore, NO values with both methods were higher in nonsmoking asthmatics than in nonsmoking healthy subjects. NO was not significantly different between exsmokers with COPD and healthy exsmokers.

In conclusion nitric oxide values of the single-breath and tidal-breathing methods are not interchangeable. Both methods can be used to measure differences between groups.

Eur Respir J 1998; 12: 816-819.
Correspondence: R.J. Meijer

Dept of Pulmonology

University Hospital Groningen

P.O. Box 30.001

9700 RB Groningen

The Netherlands

Fax: 31503619320

Keywords: Asthma

chemiluminescence

chronic obstructive pulmonary disease exhaled air

nitric oxide

smoking

Received: December 181997

Accepted after revision June 151998
Nitric oxide (NO) is produced by various cells within the respiratory tract and is detectable in exhaled air [1]. It plays an important role in the pathophysiology of airway diseases [2]. The concentration of NO is increased in patients with airway inflammation, such as asthma [3,4] and bronchiectasis [5], and is decreased by smoking in healthy subjects $[6,7]$. NO in exhaled air is comparable with NO measured directly via a bronchoscope in the central airways [8], confirming its lower airway origin in normal and asthmatic subjects. The measurement of NO has excited considerable interest as it may provide a simple, noninvasive means for monitoring airway inflammation.

Several laboratories in Europe and North America have reported measurements of exhaled NO in recent years. The values differed widely between the laboratories owing to differences in equipment and measurement techniques. To standardize methods, a European Respiratory Society (ERS) task force recently published recommendations on measurement of NO in exhaled air [9]. The task force proposed that the single-breath (SB) method was preferable in adults and the tidal-breathing (TB) method in children younger than 5 yrs, as well as in individuals who are unable to maintain steady-state exhalation during a slow exhalation manoeuvre.
No formal study measuring NO with both methods has been reported yet. Therefore, this study investigated whether there is a difference between NO values measured with these two methods in subjects with asthma or chronic obstructive pulmonary disease and in healthy subjects. Moreover, differences between groups using these two methods were studied and the influence of smoking in asthma was assessed.

\section{Patients and methods}

\section{Patients}

Sixteen nonsmoking and 16 currently smoking asthmatics, 16 exsmokers with chronic obstructive pulmonary disease (COPD), and 16 nonsmoking and 16 exsmoking healthy subjects participated in the study (table 1). The diagnosis of asthma was based on a positive history for asthma and an increase in the forced expiratory volume in one second (FEV1) of Š9\% predicted after inhalation of a $\beta_{2}$-agonist. The diagnosis of COPD was based on a positive history for COPD, an FEV1 and FEV1/vital capacity 
Table 1. - Subject characteristics

\begin{tabular}{|c|c|c|c|c|c|}
\hline & \multicolumn{2}{|c|}{ Asthma } & \multicolumn{2}{|c|}{ Healthy controls } & \multirow{2}{*}{$\frac{\text { COPD }}{\text { Exsmokers }}$} \\
\hline & Nonsmokers & Smokers & Nonsmokers & Exsmokers & \\
\hline Number & 16 & 16 & 16 & 16 & 16 \\
\hline $\mathrm{M} / \mathrm{F}$ & $5 / 11$ & $6 / 10$ & $7 / 9$ & $10 / 6$ & $15 / 1$ \\
\hline Age yrs & $28(18-44)$ & $30(21-45)$ & $28(21-47)$ & $58(47-71)$ & $63(50-74)$ \\
\hline FEV $1 \%$ pred & $77(25-113)$ & $81(41-107)$ & $109(80-132)$ & $106(91-127)$ & $57(36-79)$ \\
\hline Smoking pack-years & 0 & $9(0-35)$ & 0 & $23(10-55)$ & $33(5-69)$ \\
\hline Height $\mathrm{m}$ & $1.74(1.63-1.91)$ & $1.73(1.64-1.93)$ & $1.76(1.66-1.88)$ & $1.72(1.59-1.90)$ & $1.76(1.64-1.95)$ \\
\hline Atopy & 16 & 16 & 0 & 0 & 0 \\
\hline
\end{tabular}

Values are means and range. COPD: chronic obstructive pulmonary disease; M: male; F: female; FEV1: forced expiratory volume in one second.

$(\mathrm{VC})<$ predicted value -1.64 residual standard deviations [10] and an increase in FEV1 of $<10 \%$ pred after inhalation of a $\beta_{2}$-agonist. All 48 patients were recruited from the outpatient clinic and by advertisement in local newspapers and the healthy subjects were recruited by advertisement. Only subjects with asthma were atopic, as assessed by skin test or Phadiatop ${ }^{\mathrm{TM}}$ (Pharmacia, Uppsala, Sweden). Healthy subjects did not have a history of pulmonary disease, were not atopic as assessed by skin test or Phadiatop, and had an FEV1 and FEV1/VC S90\% of pred [10]. No subjects had a respiratory tract infection in the month preceding the study. They did not use oral or inhaled corticosteroids or antibiotics 3 weeks prior to the visit and only $\beta_{2}$-agonists were used as rescue medication. The study was approved by the hospital ethics committee and all subjects gave written informed consent.

\section{Exhaled nitric oxide}

Exhaled NO was measured using a chemiluminescence analyser (CLD 700 AL, ECO physics, Dürnten, Switzerland) with a lower detection limit of 1 part per billion (ppb) and a resolution of $\pm 1 \mathrm{ppb}$. The sampling flow was $600 \mathrm{~mL} \cdot \mathrm{min}^{-1}$ and the response time, including lag and rise time, was $<7 \mathrm{~s}$. NO was measured by SB and TB me-thod. SB: after a deep inhalation of ambient air subjects exhaled slowly, generating a flow of approximately $150 \mathrm{~mL} \cdot \mathrm{s}^{-1}$ against a built-in resistance of $6 \mathrm{kPa} \cdot \mathrm{L}^{-1} \cdot \mathrm{s}^{-1}$. The mean plateau value of three measurements in each indvidual was used for analysis. TB: subjects, wearing a noseclip, inhaled air from a Douglas bag with low NO concentration $(<3$ $\mathrm{ppb}$ ) and breathed quietly for 5 min through a two-way Hans-Rudolph ${ }^{\circledR}$ valve (Kansas City, USA). Ex-haled air was collected in a second Douglas bag from which samples were drawn. Oral pressure during SB ex-halation was $1.6 \mathrm{kPa}$. Tidal volume and minute ventilation were measured with a pneumotachograph (Jaeger, Hoechberg, Germany). Coefficients of variation of $\mathrm{NO}$ concentration measurement were $15 \%$ with the SB method and $13 \%$ with the TB method. The release rate, in nmol. $\mathrm{min}^{-1}$, was calculated by multiplying the NO concentration by the exhaled volume in $1 \mathrm{~min}$.

Spirometry was performed using a water-sealed spirometer (Lode, Groningen, The Netherlands) according to standardized guidelines. The best value of three manoeuvres was expressed as percentage of predicted (\% pred), using predicted values of the ERS [10].

\section{Analysis}

Data are expressed as means \pm SD. Differences within groups between SB and TB were tested using paired t-tests and differences between groups in NO measured with SB or TB were tested using analysis of variance (ANOVA). When a significant difference between groups was observed, intergroup comparisons were made using the Student's t-test. Differences between the SB and TB method were expressed graphically using the method of BLAND and Altman [11]. A p-value $<0.05$ was considered significant.

\section{Results}

\section{Differences between single breath and tidal breathing}

NO concentrations and release rates of the SB and TB methods within the different groups are shown in table 2 . A significant difference in NO concentration between SB

Table 2. - Mean exhaled nitric oxide (NO) concentration and release rate

\begin{tabular}{|c|c|c|c|c|}
\hline & \multicolumn{2}{|c|}{ Single breath } & \multicolumn{2}{|c|}{$\frac{\text { Tidal breathing }}{}$} \\
\hline & $\begin{array}{l}\text { NO concentration } \\
\text { ppb }\end{array}$ & $\begin{array}{c}\text { NO release rate } \\
\mathrm{nmol} \cdot \mathrm{min}^{-1}\end{array}$ & $\begin{array}{c}\text { NO concentration } \\
\text { ppb }\end{array}$ & $\begin{array}{c}\text { NO release rate } \\
\mathrm{nmol} \cdot \mathrm{min}^{-1}\end{array}$ \\
\hline Asthma, nonsmoking & $22.5(14.5)^{+\#}$ & $7.7(5.2)$ & $14.4(4.8)^{+\#}$ & $6.1(2.0)^{\S}$ \\
\hline Asthma, smoking & $16.1(10.1)^{\dagger}$ & $5.4(3.5)^{\$}$ & $11.8(7.5)$ & $4.6(2.3)$ \\
\hline Healthy control, nonsmoking & $10.8(5.6) \ddagger$ & $3.3(1.7)$ 竝 & $10.7(3.8)^{\#}$ & $4.1(1.6) \S$ \\
\hline Healthy control, exsmoking & $12.5(7.3)$ & $4.1(2.5)$ & $11.8(4.7)$ & $4.5(1.7)$ \\
\hline COPD, exsmoking & $14.0(6.2)$ & $4.8(2.5)$ & $11.6(6)$ & $5.3(2.8)$ \\
\hline
\end{tabular}

Data are expressed as mean (SD). NO: nitric oxide; COPD: chronic obstructive pulmonary disease; ppb: parts per billion. + : $\mathrm{p}=0.0038$, single breath $(\mathrm{SB})$ versus tidal breathing $(\mathrm{TB})$ in nonsmoking asthmatics; $\div \mathrm{p}=0.029$, $\mathrm{SB}$ versus $\mathrm{TB}$ in smoking asthmatics; $: \mathrm{p}=0.005$, SB method, nonsmoking asthmatics versus nonsmoking healthy controls. \#: $\mathrm{p}=0.02$, TB method, nonsmoking asthmatics versus nonsmoking healthy controls; $s$ : $\mathrm{p}=0.004$, TB method, nonsmoking asthmatics versus nonsmoking healthy controls; $\mathrm{p}=0.005$, SB method, nonsmoking asthmatics versus nonsmoking healthy controls; $\$$ : $\mathrm{p}=0.05$, SB method, smoking asthmatics versus nonsmoking healthy controls. 


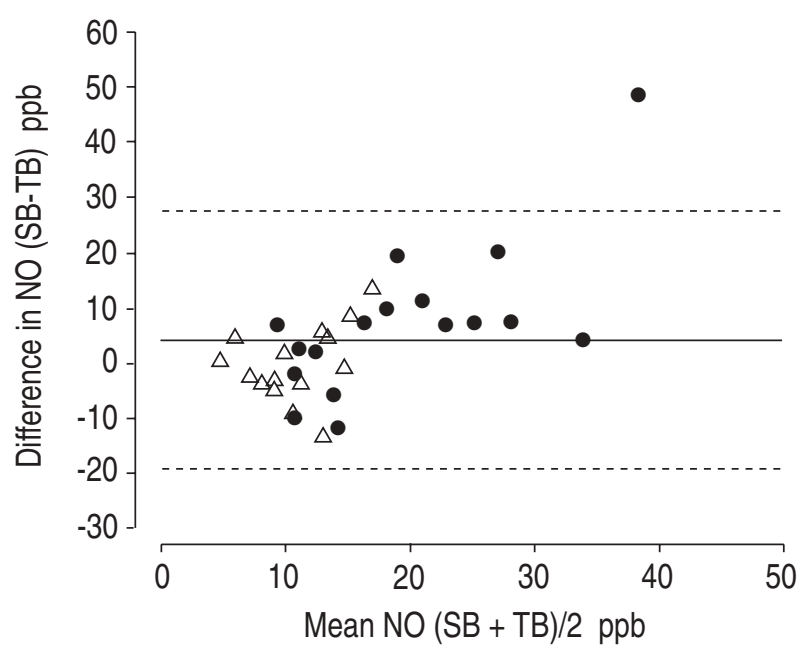

Fig. 1. - Difference in nitric oxide (NO) concentration between singlebreath (SB) and tidal-breathing (TB) measurement in nonsmoking asthmatics $(\bullet)$ and nonsmoking healthy subjects $(\Delta)$. The mean of SB and TB measured NO concentration of each subject is plotted against the difference between SB and TB measured NO concentration [11].—mean difference between SB and TB values; - - - - -: limits of agreement for the whole group (mean value $\pm 2 \mathrm{SD}$ ).

and TB was found in smoking and nonsmoking asthmatics, but not in exsmokers with COPD or in healthy subjects. The mean difference between the two methods was largest for nonsmoking asthmatics (8 ppb, table 2) and increased with higher NO levels (fig. 1). The mean difference in NO concentration between SB and TB method was $2 \mathrm{ppb}$ in exsmokers with COPD and exsmoking healthy subjects (fig. 2). NO release rates were not significantly different in any group when comparing the SB with the TB method.

\section{Differences between groups}

A significant difference in NO values between nonsmoking asthmatics and healthy subjects was found, irrespec-

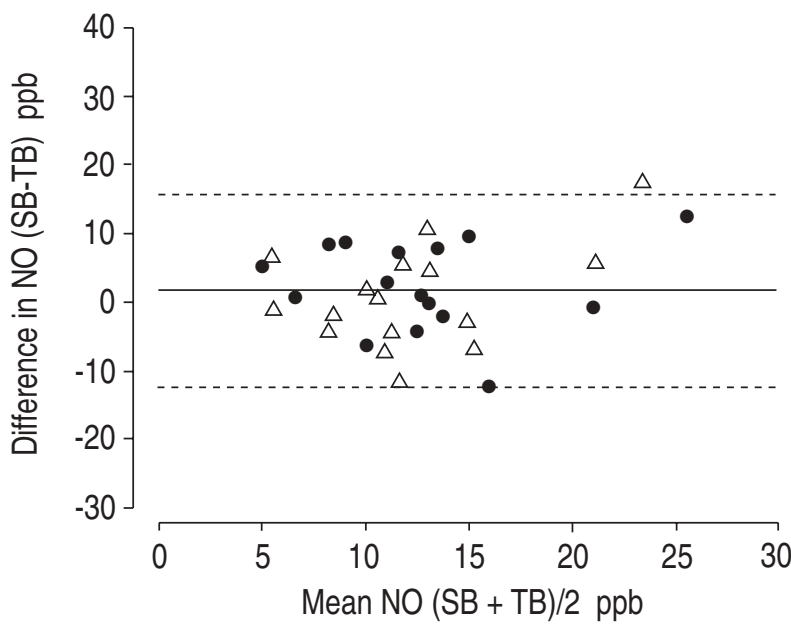

Fig. 2. - Difference in nitric oxide (NO) concentration between singlebreath (SB) and tidal-breathing (TB) measurement in exsmokers with chronic obstructive pulmonary disease $(\bullet)$ and healthy exsmokers $(\Delta)$. The mean of SB and TB measured NO concentration of each subject is plotted against the difference between SB and TB measured NO concentration [11]. — : mean difference between SB and TB values; - - - - -: limits of agreement for the whole group (mean value $\pm 2 \mathrm{SD}$ ). tive of the method used or the expression in concentrations or release rates. Only the SB release rate showed a significant difference between smoking asthmatics and healthy nonsmokers $(\mathrm{p}=0.05)$. The upper $95 \%$ confidence limits of NO concentration of healthy subjects were 20 and 17 ppb with the SB and the TB method, respectively. Eleven asthmatics had higher NO concentrations than these limits with the SB and three with the TB method, yielding a sensitivity for the detection of asthma of 69 and 19\%, respectively, for these two methods. Smoking asthmatics tended to have lower NO concentrations than nonsmoking asthmatics, as measured with the SB method $(\mathrm{p}=0.08)$ but not with the TB method $(p=0.20)$. No significant difference in NO values, as measured with both methods, were found between exsmokers with COPD and healthy exsmokers.

\section{Discussion}

Mean NO concentrations were higher with the SB than with the TB method in both nonsmoking and smoking asthmatics. The limits of agreement between the two methods were wide in both diseases. In nonsmoking asthmatics, the difference between the SB and the TB method increased with higher NO. Furthermore, NO was higher in nonsmoking asthmatics than in healthy subjects with both the SB and the TB method. NO tended to be higher in nonsmoking asthmatics than in smoking asthmatics. NO was not significantly different between exsmokers with COPD and healthy exsmokers.

The results show that NO values obtained with the SB and the TB method are not interchangeable. The SB method yields higher values than the TB method, especially with the higher NO values. This is particularly important in subjects with asthma, in whom NO levels are generally higher. Therefore, any comparison of study results using the above-mentioned methods should be made with caution.

Several differences between the SB and TB methods may contribute to the differences in NO concentration found. These include inhaled air dilution, flow, nasal leakage and breath holding. The first two factors may contribute to the higher NO concentrations measured with the SB than with the TB method, whereas the latter would cause the NO values to be lower with the SB than with the TB method. NO concentrations in inhaled air are generally lower than the concentrations generated in the lower airways. The very first part of the exhalation consists of this inhaled air and has, therefore, a lower NO concentration than the rest of the exhalation. This first part of the exhalation is discarded in the SB but not in the TB method, thereby decreasing NO concentration via dilution in the latter.

Differences in flow and breathing pattern may also cause differences in NO values. Flow has been shown to influence exhaled NO values markedly in a nonlinear fashion [12]. The flow is constant and standardized to 150 $\mathrm{mL} \cdot \mathrm{s}^{-1}$ in the SB method. In the TB method, the flow varies during the breath cycle, while the mean flow is comparable with SB flow. If the flow stops during the breathing cycle, NO is not transported towards the mouth and the net result may be more metabolism, uptake in the airway lining fluid or binding to haemoglobin [13]. Similar average flows, therefore, do not necessarily imply similar NO transport with exhaled air. Higher NO metabolism, uptake 
in the airway lining fluid or binding to haemoglobin may contribute further to lower NO concentrations with the TB method.

Leakage of NO from the nose into the trachea is thought to be more important with the TB than the SB method, because subjects exhale against a low resistance of $6 \mathrm{kPa}$. $\mathrm{L}^{-1} \cdot \mathrm{S}^{-1}$ with the latter method. Since NO concentrations in the nose have been found to be generally higher than in the lower airways [3], this effect would falsely augment the NO concentration in the TB method, as was observed in some patients.

Breath holding has been shown to increase NO concentrations in exhaled air, especially in the first part of exhalation [14]. This first part is discarded in the SB method but not in the TB method, and may contribute to the measured NO value in the latter. The time between inhalation and exhalation may vary during $\mathrm{TB}$, thus making the effects of breath holding possible. Breath holding may, therefore, cause higher NO concentrations with the TB than with the SB method, especially when the breathing frequency is low.

From the above-mentioned points, it can be expected that the TB method is less accurate in measuring lower airway NO than the SB method. This can partly be improved by using a system of valves at the mouth, by which the first part of the exhaled air can be discarded. In addition, by introducing a small resistance, as in the SB method, nasal contamination could be controlled and flow could be standardized to a larger extent. It remains to be determined whether such a modification yields similar NO concentrations between SB and TB methods.

This study confirms the findings of previous studies showing asthmatics to have higher NO concentrations than healthy subjects $[3,4]$ and extends these findings by showing that asthmatic smokers tend to have lower NO values than nonsmoking asthmatics but higher than healthy nonsmokers. Therefore, the effects of current smoking are not present in healthy subjects only [6,7] but also in asthmatics.

To our knowledge this is the first reported study on exhaled NO in which exsmokers with COPD were compared with age- and smoking-matched healthy subjects, thereby extending the findings from a recent report [15]. In contrast to asthmatics, subjects with COPD do not have higher exhaled NO concentrations than healthy subjects. This may be explained by a difference in the type, number or activation state of inflammatory cells between asthma and COPD [15].

In conclusion, nitric oxide values of the single-breath and tidal-breathing methods are not interchangeable. Nevertheless, both methods can be used to measure differences between groups. It remains to be determined whether both methods are also useful for the longitudinal measurement of nitric oxide.

\section{References}

1. Gustafsson LE, Leone AM, Persson NIG, Wiklund NP, Moncada S. Endogenous nitric oxide is present in the exhaled air of rabbits, guinea-pigs and humans. Biochem Biophys Res Commun 1991; 181: 852-857.

2. Gaston B, Drazen JM, Loscalzo J, Stamler JS. The biology of nitrogen oxides in the airways. Am J Respir Crit Care Med 1994; 149: 538-551.

3. Alving K, Weitzberg E, Lundberg JM. Increased amount of nitric oxide in exhaled air of asthmatics. Eur Respir $J$ 1993; 6: 1368-1370.

4. Kharitonov SA, Yates D, Robbins RA, Logan-Sinclair R, Shinebourne EA, Barnes PJ. Increased nitric oxide in exhaled air of asthmatic patients. Lancet 1994; 343: 133135.

5. Kharitonov SA, Wells AU, O'Connor BJ, et al. Elevated levels of exhaled nitric oxide in bronchiectasis. Am J Respir Crit Care Med 1995; 151: 1889-1893.

6. Persson MG, Zetterstrom O, Agrenius V, Ihre E, Gustafsson LE. Single-breath nitric oxide measurements in asthmatic patients and smokers. Lancet 1994; 343: 146-147.

7. Kharitonov SA, Robbins RA, Yates D, Keatings V, Barnes PJ. Acute and chronic effects of cigarette smoking on exhaled nitric oxide. Am J Respir Crit Care Med 1995; 152: 609-612.

8. Massaro AF, Mehta S, Lilly CM, Kobzik L, Reilly JJ, Drazen JM. Elevated nitric oxide concentrations in isolated lower airway gas of asthmatic subjects. Am J Respir Crit Care Med 1996; 153: 1510-1514.

9. Kharitonov SA, Alving K, Barnes M. Exhaled and nasal nitric oxide measurements: recommendations. Eur Respir J 1997; 10: 1683-1693.

10. Quanjer PH, Tammeling GJ, Cotes JE, Pedersen OF, Peslin R, Yernault J-C. Lung volumes and forced ventilatory flows. Eur Respir J 1993; 6: Suppl. 16, 5-40.

11. Bland JM, Altman DG. Statistical methods for assessing agreement between two methods of clinical measurement. Lancet 1986; i: 307-310.

12. Silkoff PE, McClean PA, Slutsky AS, et al. Marked flow-dependence of exhaled nitric oxide using a new technique to exclude nasal nitric oxide. Am J Respir Crit Care Med 1997; 155: 260-267.

13. Hyde RW, Geigel EJ, Olszowka AJ, et al. Determination of production of nitric oxide by lower airways of humans theory. J Appl Physiol 1997; 82: 1290-1296.

14. Kimberley B, Nejadnik B, Giraud GD, Holden WE. Nasal contribution to exhaled nitric oxide at rest and during breathholding in humans. Am J Respir Crit Care Med 1996; 153: 829-836.

15. Maziak W, Loukides S, Culpitt S, Sullivan P, Kharitonov SA, Barnes PJ. Exhaled nitric oxide in chronic obstructive pulmonary disease. Am J Respir Crit Care Med 1998; 157: 998-1002.

16. Jeffery PK. Comparative morphology of the airways in asthma and chronic obstructive pulmonary disease. Am J Respir Crit Care Med 1994; 150: S6-13. 